BMJ Paediatrics Open

\title{
Interventions to treat pain in paediatric CFS/ME: a systematic review
}

Caitlin Ascough (D , ${ }^{1}$ Hayley King, ${ }^{1}$ Teona Serafimova, ${ }^{1}$ Lucy Beasant, ${ }^{1}$ Sophie Jackson, ${ }^{1}$ Luke Baldock, ${ }^{1}$ Anthony Edward Pickering, ${ }^{2,3}$ Jonathan Brooks, ${ }^{4}$ Esther Crawley (iD ${ }^{1}$

To cite: Ascough C, King $\mathrm{H}$, Serafimova $\mathrm{T}$, et al. Interventions to treat pain in paediatric CFS/ME: a systematic review. BMJ Paediatrics Open 2020;4:e000617. doi:10.1136/ bmjpo-2019-000617

- Additional material is published online only. To view please visit the journal online (http://dx.doi.org/10.1136/ bmjpo-2019-000617).

Received 26 November 2019 Revised 6 January 2020 Accepted 8 January 2020
Check for updates

\section{(C) Author(s) (or their} employer(s)) 2020. Re-use permitted under CC BY-NC. No commercial re-use. See rights and permissions. Published by BMJ.

${ }^{1}$ Centre for Academic Child Health, Bristol Medical School, University of Bristol, Bristol, UK ${ }^{2}$ School of Physiology, Pharmacology and Neuroscience, University of Bristol, Bristol, UK

${ }^{3}$ Bristol Anaesthesia, Pain \& Critical Care Sciences, Translational Health Sciences, Bristol Medical School, University of Bristol, Bristol, UK ${ }^{4}$ School of Psychological Science, University of Bristol, Bristol, UK

Correspondence to Dr Caitlin Ascough; caitlin. ascough@bristol.ac.uk

\section{ABSTRACT}

Background Paediatric chronic fatigue

syndrome/myalgic encephalomyelitis (CFS/ME) is common (prevalence 1\%-2\%). Two-thirds of children experience moderate or severe pain, which is associated with increased fatigue and poorer physical function. However, we do not know if treatment for CFS/ME improves pain. Objective Identify whether specialist treatment of paediatric CFS/ME improves pain.

Methods We conducted a detailed search in MEDLINE, EMBASE, PsycINF0 and the Cochrane Library. Two researchers independently screened texts published between 1994 and 24 January 2019 with no language restrictions. Inclusion criteria were (1) randomised controlled trials and observational studies; (2) participants aged $<19$ years with CFS/ME; and (3) measure of pain before and after an intervention.

Results of 1898 papers screened, 26 studies investigated treatment for paediatric CFS/ME, 19 of which did not measure pain at any time point. Only five treatment studies measured pain at baseline and follow-up and were included in this review. None of the interventions were specifically targeted at treating pain. Of the included studies, two showed no improvement in pain scores, one suggested an improvement in one subgroup and two studies identified improvements in pain measures in 'recovered' patients compared with 'non-recovered' patients.

Conclusions Despite the prevalence and impact of pain in children with CFS/ME surprisingly few treatment studies measured pain. In those that did measure pain, the treatments used focused on overall management of CFS/ ME and we identified no treatments that were targeted specifically at managing pain. There is limited evidence that treatment helps improve pain scores. However, patients who recover appear to have less pain than those who do not recover. More studies are needed to determine if pain in paediatric CFS/ME requires a specific treatment approach, with a particular focus on patients who do not recover following initial treatment.

PROSPERO registration number CRD42019117540.

\section{INTRODUCTION}

Paediatric chronic fatigue syndrome (CFS) / myalgic encephalomyelitis (ME) is relatively common and causes significant suffering for children and their families. ${ }^{1-3}$ It affects $1 \%-2 \%$ of UK adolescents and is associated

\section{What is known about the subject?}

- Chronic fatigue syndrome/myalgic encephalomyelitis (CFS/ME) is prevalent $(1 \%-2 \%)$ in adolescents and nearly two-thirds of patients report moderate or severe pain.

- Pain is associated with worse fatigue and poorer physical function in adolescents with CFS/ME.

\section{What this study adds?}

- Despite the prevalence and impact of pain in children with CFS/ME few treatment studies have measured pain as an outcome and no interventions targeted pain.

- There is insufficient evidence to suggest that the treatment of fatigue also improves pain in paediatric CFS/ME.

- Patients who recover from CFS/ME appear to have less pain at follow-up than those who do not recover.

with low mood, poor quality of life and a mean total loss of school attendance of 1 year. ${ }^{45}$ In addition to fatigue, children and young people experience a range of symptoms including headaches, muscle and joint pain and sore throats. ${ }^{6}$

Pain is a common and disabling symptom in children with CFS/ME. Over $60 \%$ of CFS/ ME children experience moderate or severe pain (as evidenced by a pain visual analogue scale $>40 / 100)$ and this is associated with worse fatigue and poorer physical function. ${ }^{67}$ This is much higher than in healthy children where between $3.6 \%$ and $16.6 \%$ will describe severe pain. ${ }^{8}$ In adult patients with CFS/ME pain is associated with worse outcomes. ${ }^{79}$

However, the aetiology and pathophysiology of pain in this population is poorly understood and current treatment approaches do not target pain. ${ }^{1011}$ This systematic review aimed to identify what interventions, if any, have been used to treat pain in children with CFS/ $\mathrm{ME}$, and to establish whether interventions 
used to treat paediatric CFS/ME change pain scores at follow-up.

\section{METHODS}

This review was conducted in accordance with the Preferred Reporting Items for Systematic Reviews and Meta-Analyses statement and the Cochrane Handbook 6.0. ${ }^{12} 13$ The protocol was prospectively registered on PROSPERO (https://www.crd.york.ac.uk/prospero).

\section{Search strategy}

We performed a detailed literature search in MEDLINE, EMBASE, PsycINFO and the Cochrane Library. The search strategy was developed in conjunction with a data specialist at the University of Bristol. It was adapted appropriately for each database and there were no language restrictions. We searched the trial registration websites for unpublished trials and hand searched reference lists of all included studies. Full details of the search strategy can be seen in online supplementary appendix 1. We searched only for studies published since 1994, as this is when the Centers for Disease Control and Prevention (CDC) definition of CFS/ME was introduced, ${ }^{14}$ and included articles published until 24 January 2019.

\section{Eligibility criteria}

We included randomised controlled trials (RCT) and observational studies that investigated a treatment or intervention in patients $<19$ years of age with CFS/ ME. A diagnosis of CFS/ME was determined according to National Institute for Health and Care Excellence, ${ }^{11}$ CDC (Fukuda 2004) ${ }^{14}$ or Oxford ${ }^{15}$ criteria. Studies were eligible if they described a measure of pain (quantitative, qualitative or mixed methods) before and after an intervention. Studies that described self-reported symptoms such as 'abdominal discomfort' and 'muscle aches' were excluded unless they also included an objective or subjective measure of pain.

\section{Study selection}

Two researchers independently screened the abstracts of all studies generated from the literature search. Any discrepancies were discussed and resolved, if necessary, with a third reviewer. The researchers then independently reviewed the full texts of all potentially eligible studies. To identify all available evidence, we reviewed the full text of all studies that described interventions in paediatric CFS/ME. Any studies involving patients both above and below 19 years of age were also reviewed at full text to establish if there were separate data for patients under 19 years.

\section{Data extraction}

Two researchers extracted the data from all studies that met the inclusion criteria using a purpose-designed data extraction form. We collected data on study characteristics (study type, country, sample size), intervention characteristics (type, length of course), pain characteristics (type, severity, pain measure used) and change in pain measure from baseline to follow-up.

\section{Assessment of risk of bias}

The risk of bias was evaluated in all studies for outcomes relating to pain. The four RCTs were evaluated using the Revised Cochrane Risk of Bias tool for randomised trials. ${ }^{16}$ One study reported pain and assessment in a longitudinal cohort derived from an RCT. We chose to evaluate this using the Risk of Bias In Non-Randomized Studies of Interventions (ROBINS-I) tool. ${ }^{17}$ Assessment was conducted by two independent assessors, who resolved disagreements by discussion.

\section{Data synthesis}

We performed a descriptive analysis of the results, taking into account the methodological quality of the evidence. There was substantial heterogeneity between studies, and we were therefore unable to perform a meta-analysis.

\section{Patient and public involvement}

A young person's CFS/ME patient advisory group identified pain in fatigue as an important topic for further research.

\section{RESULTS}

\section{Summary of included studies}

Figure 1 describes the search results and study selection process. The search identified 1898 studies, of which we reviewed 107 full-text papers for eligibility. Six papers were eligible for inclusion with data from five studies. ${ }^{18-23}$ Papers were considered to be ineligible because: they did not include patients with CFS/ME $<19$ years of age $(\mathrm{n}=65)$; measure pain $(\mathrm{n}=19)$; measure pain at both time points $(n=2)$; describe an intervention $(n=1)$; or because they were not published papers of RCTs/observational studies $(\mathrm{n}=14)$.

Table 1 details the characteristics of the included studies. Of these studies, four were RCTs and one was an observational study. The total sample size consisted of 414 adolescents aged between 10 and 18 years with a diagnosis of CFS/ME.

Figure 2 describes the risk of bias in the RCTs. One was deemed low risk of bias and one was deemed moderate risk of bias. The remaining two were at high risk of bias following assessment. The ROBINS-I tool suggested the longitudinal cohort study following an RCT was at high risk of bias. Due to the paucity of studies that measured pain outcomes in paediatric CFS/ME all studies were included in the review and the risk of bias was taken into account when evaluating study findings.

Pain measurement in treatment studies of paediatric CFS/ME In total, we identified 26 RCTs or observational studies that investigated treatment interventions in paediatric CFS/ ME. However, 19 of these studies did not measure pain at any time point, ${ }^{24-43}$ and two studies measured pain at a single time point only. ${ }^{1044}$ They were therefore excluded 


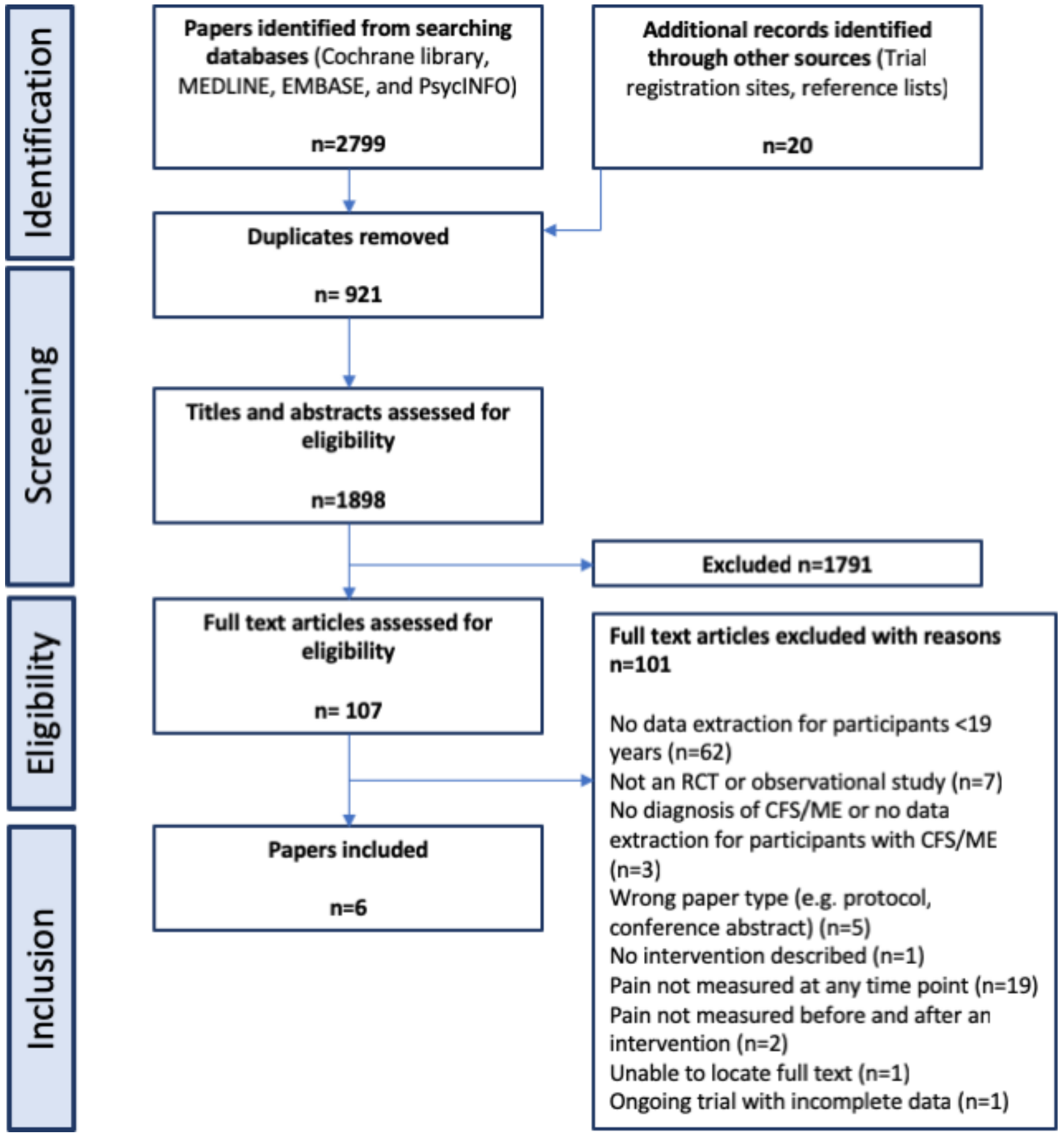

Figure 1 Preferred Reporting Items for Systematic Reviews and Meta-Analyses (PRISMA) flow diagram detailing the study selection process. CFS, chronic fatigue syndrome; ME, myalgic encephalomyelitis; RCT, randomised controlled trial.

from this review. Four of the studies included the prevalence of self-reported symptoms, for example, muscle aches, abdominal discomfort and tender lymph nodes, but did not include measures of pain severity. ${ }^{24253141}$ The remaining studies did not discuss pain at all.

Within the included studies, the pain measures used were heterogeneous. Three of the five studies used validated pain questionnaires: a Pain Visual Analogue Scale, ${ }^{45}$ Child Health Questionnaire-87 Bodily Pain Subscale ${ }^{46}$ and Brief Pain Inventory. ${ }^{47}$ The remaining two studies, conducted at the same centre, used a mean Daily Observed Pain (DOP) score calculated from a Likert scale of 1 (no pain) to 4 (severe pain) recorded four times a day for 12 consecutive days. Only one study attempted to measure pain using algometry. ${ }^{21}$

Interventions used to treat pain in paediatric CFS/ME

The included studies described a range of interventions used to treat children with CFS/ME (table 2). However, none of the interventions were specifically targeted at treating pain.

All treatments were delivered in the outpatient setting. One of the studies investigated a pharmacological intervention (low-dose clonidine) ${ }^{22}$ and four studies described 
Table 1 Study characteristics

\begin{tabular}{|c|c|c|c|c|c|c|c|}
\hline Author, year & Country & $\begin{array}{l}\text { Study } \\
\text { design }\end{array}$ & Intervention & $\begin{array}{l}\text { Sample at } \\
\text { baseline } \\
\text { (n) }\end{array}$ & $\begin{array}{l}\text { Sample at } \\
\text { follow-up, } n \\
\text { (\% baseline) }\end{array}$ & $\begin{array}{l}\text { Mean age } \\
\text { (range) }\end{array}$ & Follow-up \\
\hline $\begin{array}{l}\text { Crawley et al, } \\
2013^{18} \\
2018^{19}\end{array}$ & UK & $\mathrm{RCT}$ & $\begin{array}{l}\text { Specialist care and } \\
\text { Lightning Process } \\
\text { versus specialist care } \\
\text { alone }\end{array}$ & 100 & $\begin{array}{l}61(61) \\
59(59)\end{array}$ & 14 & $\begin{array}{l}6 \text { months } \\
12 \text { months }\end{array}$ \\
\hline $\begin{array}{l}\text { Knoop et al, } \\
2007^{20} 41 \\
\text { (Analysis of } \\
\text { data from } \\
\text { Stulemeijer et } \\
\text { al, 2005) }\end{array}$ & Netherlands & $\mathrm{RCT}$ & CBT versus waiting list & 69 & $66(96)$ & $15.6(10-17.2)$ & 5 months \\
\hline $\begin{array}{l}\text { Nijhof et al, } \\
2013^{21}\end{array}$ & Netherlands & $\begin{array}{l}\text { Cohort } \\
\text { study }\end{array}$ & $\begin{array}{l}\text { CBT (internet delivered } \\
\text { or face to face) }\end{array}$ & 83 & $72(87)$ & $15.8(12-18)$ & 12 months \\
\hline $\begin{array}{l}\text { Sulheim et } \\
\text { al,2014 }\end{array}$ & Norway & $\mathrm{RCT}$ & $\begin{array}{l}\text { Low-dose clonidine } \\
\text { versus placebo }\end{array}$ & 120 & $\begin{array}{l}106(88) \\
103(86)\end{array}$ & $15.4(12-18)$ & $\begin{array}{l}8 \text { weeks } \\
30 \text { weeks }\end{array}$ \\
\hline $\begin{array}{l}\text { van Geelen et } \\
\text { al, } 2011^{23}\end{array}$ & Netherlands & $\mathrm{RCT}$ & $\begin{array}{l}6 \text { sessions of self- } \\
\text { confrontation method } \\
\text { versus } 12 \text { sessions } \\
\text { of self-confrontation } \\
\text { method }\end{array}$ & 42 & $35(83)$ & 16.5 & $\begin{array}{l}4 \text { months } \\
14 \text { months }\end{array}$ \\
\hline
\end{tabular}

CBT, cognitive-behavioural therapy; RCT, randomised controlled trial.

behavioural interventions. ${ }^{19-21} 23$ Behavioural interventions used were heterogeneous. Two of the trials used cognitive-behavioural therapy (CBT), however, the structure of the treatment varied. CBT was delivered as both a face-to-face intervention and an online intervention, and the number of sessions ranged from 10 to 22. One trial investigated the Lightning Process which is developed from life coaching and neurolinguistics programming, and another used a programme of self-confrontation, a

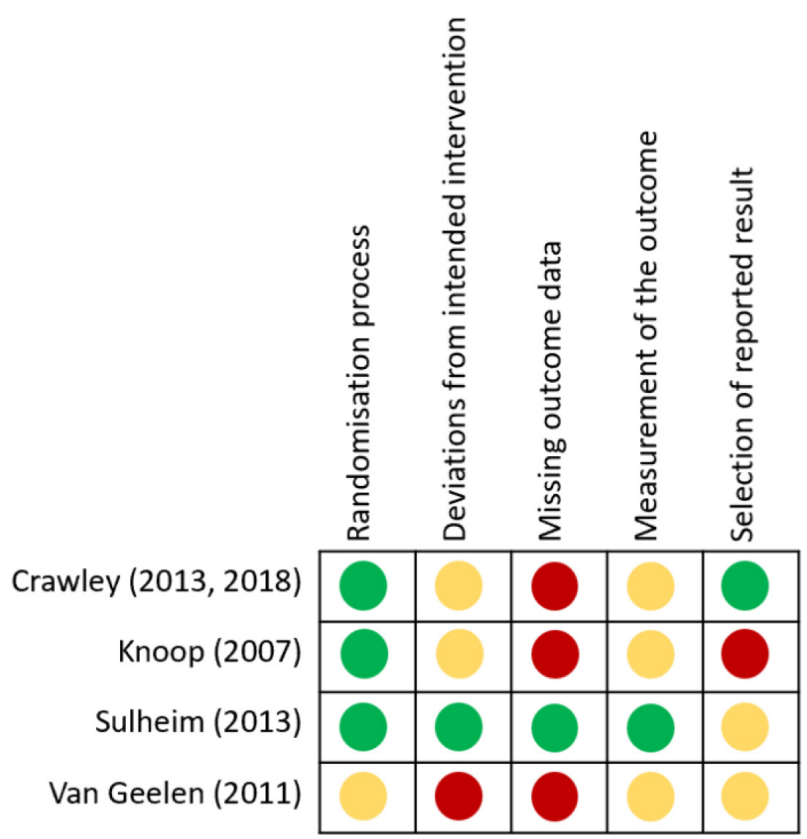

Figure 2 Assessment of risk of bias using the Revised Cochrane Risk of Bias tool for randomised trials (RoB 2). ${ }^{16}$ method used to 'assess and change individual life stories through narrative self-investigation'. ${ }^{23}$

\section{Change in pain scores following treatment}

The results of each study are presented in table 2. Two RCTs showed no improvement in pain scores following treatment. ${ }^{1922}$ One of these trials, conducted in a sample of 100 patients from the UK, investigated the effectiveness of the Lightning Process in addition to specialist medical care compared with specialist medical care alone. In this trial, fatigue, anxiety, depression and school attendance improved. Pain, measured on a Visual Analogue Scale (0-100), was similar between assessment and follow-up at 6 months (adjusted difference in means -9.3 (95\% CI -21.1 to $2.6, \mathrm{p} 0.124)) .{ }^{19}$ The second trial investigated treatment with low-dose clonidine and found no change in scores on a Brief Pain Inventory compared with a placebo. ${ }^{22}$ These studies were at a moderate and low risk of bias, respectively.

The remaining three studies reported some improvement in pain measures. ${ }^{202123}$ Two of the studies compared DOP scores in patients who were deemed to have 'recovered' from CFS/ME with those who had 'not recovered'. 2021 Different definitions of recovery were used in each study. One of the largest trials to date enrolled a subgroup of patients from the Fatigue In Teenagers on the Internet study in the Netherlands and reported an association between 'recovery' from CFS/ME and improved pressure pain thresholds and DOP scores. All participants were treated with 6 months of internetbased or face-to-face CBT and follow-up measures were obtained at 12 months. After the trial was reported, the 
Table 2 Study results

\begin{tabular}{|c|c|c|c|c|}
\hline Author, year & $\begin{array}{l}\text { Description of } \\
\text { intervention }\end{array}$ & $\begin{array}{l}\text { Intervention } \\
\text { targeted at } \\
\text { treating pain? }\end{array}$ & Pain measure used & $\begin{array}{l}\text { Change in pain score } \\
\text { following intervention }\end{array}$ \\
\hline $\begin{array}{l}\text { Crawley et al, } \\
2013^{18} 2018^{19}\end{array}$ & $\begin{array}{l}\text { Lightning Process } \\
\text { course of } 3 \times 4 \text { hour } \\
\text { sessions on } \\
\text { consecutive days in } \\
\text { small groups }\end{array}$ & No & Pain Visual Analogue Scale & $\begin{array}{l}\text { Intervention group versus } \\
\text { control group } \\
-9.3 \text { ( }-21.1 \text { to } 2.6), p=0.124 \\
\text { at } 6 \text { months } \\
-6.5 \text { ( }-19.4 \text { to } 6.5), p=0.321 \\
\text { at } 12 \text { months }\end{array}$ \\
\hline $\begin{array}{l}\text { Knoop et al, } \\
2007^{20} \text { (Analysis } \\
\text { of data from } \\
\text { Stulemeijer et al, } \\
2005)^{41}\end{array}$ & $\begin{array}{l}\text { CBT } \\
10 \text { sessions in } 5 \\
\text { months } \\
\text { Two CBT protocols } \\
\text { were used. One was } \\
\text { for patients with a } \\
\text { passive physical } \\
\text { activity pattern and } \\
\text { another for relatively } \\
\text { active patients. }\end{array}$ & No & $\begin{array}{l}\text { Mean Daily Observed Pain } \\
\text { (DOP) score calculated from a } \\
\text { Likert scale of } 1 \text { (no pain) to } 4 \\
\text { (very severe pain) done } 4 \times \text { per } \\
\text { day for } 12 \text { days. } \\
\% \text { of patients with pain level } \\
\text { within range of healthy controls } \\
\text { defined as DOP score }<2.3 \text {. }\end{array}$ & $\begin{array}{l}\text { Change in DOP score of } \\
\text { CBT group versus waiting list } \\
\text { control } \\
-2.21(\mathrm{SD}=3.85) \text { vs }-0.36 \\
(\mathrm{SD}=2.19) \\
\mathrm{T}=-2.44, \mathrm{p}=0.04 \\
\% \text { of participants with DOP } \\
\text { score within range of healthy } \\
\text { controls in CBT group versus } \\
\text { waiting list group } \\
56 \% \text { vs } 29 \%\left(\chi^{2} 4.38, \mathrm{df}=1 \text {, }\right. \\
\mathrm{p}=0.04)\end{array}$ \\
\hline Nijhof et al, $2013^{21}$ & $\begin{array}{l}\text { CBT } \\
6 \text {-month course of } \\
\text { either internet-based } \\
\text { (FITNET) or face-to- } \\
\text { face CBT }\end{array}$ & No & $\begin{array}{l}\text { Mean DOP score calculated } \\
\text { from a Likert scale of } 1 \text { (no } \\
\text { pain) to } 4 \text { (very severe pain) } \\
\text { done } 4 \times \text { per day for } 12 \text { days. } \\
\text { Average pressure pain } \\
\text { threshold }(\mathrm{kg}) \text {. }\end{array}$ & $\begin{array}{l}\text { Recovered group versus non- } \\
\text { recovered group } \\
\text { Average DOP }-2.9(-4.2 \text { to } \\
1.6), p=<0.001 \\
\text { Average pain threshold }+1.2 \\
(0.2-2.2), p=0.019\end{array}$ \\
\hline
\end{tabular}

CBT, cognitive-behavioural therapy; CHQ, Child Health Questionnaire; FITNET, Fatigue in Teenagers on the Internet.

authors submitted an additional peer-reviewed letter to the editor evaluating pain. Here, they compared pain levels in those who had recovered to those who had not recovered. Within this, they described higher mean pressure pain thresholds and lower mean DOP scores in 'recovered' patients (39 of 72 patients) compared with 'non-recovered' patients. However, due to a relatively small sample size, CIs were large, the study was not controlled and the risk of bias was high. ${ }^{21}$

Another study, with a moderate risk of bias, presented a post hoc analysis of data that had not previously been reported in an original RCT, comparing CBT to a 'waiting list' control. Following 10 sessions of CBT 21/32 patients were classed as 'recovered' and had lower mean DOP scores than 'non-recovered' patients. This finding was replicated when comparing patients receiving CBT with the waiting list control group. However, the mean DOP score in adolescents, who had completed the course of CBT but were not classed as 'recovered', increased at 6-month follow-up. ${ }^{20}$

The final study assessed a 'self-confrontation method' of behavioural therapy that is not used in the National Health Service (NHS). Patients who received 12 sessions of self-confrontation exhibited improved scores on a Bodily Pain Subscale at 4 months, whereas patients who received six sessions had no significant change. Sample 
sizes in each group were small, CIs were large and the risk of bias was high. ${ }^{23}$

\section{DISCUSSION}

This is the first systematic review investigating the interventions used to treat pain in paediatric CFS/ME and whether they change pain scores at follow-up. We did not identify any interventions that specifically targeted pain. Surprisingly few of the CFS/ME intervention studies $(<20 \%)$ identified measured pain despite the fact that pain is one of the most common and important patient-reported outcomes experienced by children with CFS/ME. In those studies that did measure pain, there is limited evidence that specialist CFS/ME treatment improves pain scores. However, in those who do recover, pain appears to be less compared with those who do not recover.

\section{Strengths and limitations}

The strengths of this study include its comprehensive search strategy and rigorous study selection process. We ran a detailed search in four databases, hand searched reference lists for additional papers and, in order to reduce the risk of publication bias, hand searched trial registration websites to identify unpublished studies. We included papers that were not written in the English language. During screening two independent researchers reviewed the full texts of all treatment studies in children with CFS/ME to ensure that we identified any studies in which pain was measured as a secondary outcome but not discussed in the abstract.

This review has a number of limitations. Substantial heterogeneity in the pain measures used and intervention types made comparison between studies challenging and we were unable to carry out a meta-analysis. Four studies were excluded because the secondary outcomes measured were ambiguous and it was not possible to confirm the presence or degree of pain. This included self-reported symptoms such as 'abdominal discomfort', 'muscle aches' and 'tender lymph nodes'.

In addition to this, none of the studies reported data on the use of pain medications by participants. It is therefore unclear to what extent pain medications may be responsible for improvements in pain scores. Further, one of the studies involved clonidine as an intervention. While this was employed to attenuate sympathetic and adrenocortical hyperactivity, it is also known to have an analgesic action.

One study compared different durations of the same intervention (self-confrontation method). Improved pain scores cited following 12 self-confrontation sessions could be a consequence of an increased number of sessions or represent the natural time course of the pain.

Almost all the studies were conducted outside of the UK and therefore the findings may not be applicable to the NHS. All patients were referred from secondary care and therefore the results may not be generalisable to patients looked after in a primary care setting. The generalisability of the findings is also limited by the fact that two of the studies excluded patients with psychiatric comorbidities and another study only included patients with mild or moderate CFS/ME.

We were also unable to locate one full-text paper despite contacting the author directly, and at the time of publication there are two ongoing randomised controlled treatment trials in paediatric $\mathrm{CFS} / \mathrm{ME}^{48}{ }^{49}$ for which results are not yet available.

\section{CONCLUSION}

Despite the prevalence and impact of pain in children with CFS/ME, it is surprising how few treatment studies have measured pain. There is limited evidence that current treatments improve pain in paediatric CFS/ME, especially in patients who do not recover following initial treatment. Future research should investigate appropriate methods to measure pain in children with CFS/ ME. This will enable large, well-powered RCTs investigating different treatment approaches to pain in this population.

Contributors CA conducted the review and wrote the first draft of the paper. CA, HK, LB and SJ reviewed the titles and abstracts and extracted the data. TS and LB completed the risk of bias assessments. AP and JB advised on the interpretation of pain scores. The idea for the study was EC's. All the authors reviewed the drafts of the paper and all approved the final submitted version.

Funding This work was supported by the UKFPO Academic Foundation Programme.

Competing interests One of the authors of this systematic review (EC) was also an author of one of the included papers. However, to avoid a conflict of interest, EC was not involved in the study selection, data extraction or assessment of risk of bias.

Patient consent for publication Not required.

Provenance and peer review Not commissioned; externally peer reviewed.

Data availability statement All data relevant to the study are included in the article or uploaded as supplementary information. All data generated or analysed during this study are included in this published article (and its supplementary information files).

Open access This is an open access article distributed in accordance with the Creative Commons Attribution Non Commercial (CC BY-NC 4.0) license, which permits others to distribute, remix, adapt, build upon this work non-commercially, and license their derivative works on different terms, provided the original work is properly cited, appropriate credit is given, any changes made indicated, and the use is non-commercial. See: http://creativecommons.org/licenses/by-nc/4.0/.

\section{ORCID iDs}

Caitlin Ascough http://orcid.org/0000-0002-2266-3433

Esther Crawley http://orcid.org/0000-0002-2521-0747

\section{REFERENCES}

1 Rangel L, Garralda ME, Levin M, et al. The course of severe chronic fatigue syndrome in childhood. J R Soc Med 2000;93:129-34.

2 Crawley E. The epidemiology of chronic fatigue syndrome/myalgic encephalitis in children. Arch Dis Child 2014;99:171-4.

3 Parslow R, Patel A, Beasant L, et al. What matters to children with CFS/ME? A conceptual model as the first stage in developing a PROM. Arch Dis Child 2015;100:1141-7.

4 Crawley E, Sterne JAC. Association between school absence and physical function in paediatric chronic fatigue syndrome/myalgic encephalopathy. Arch Dis Child 2009;94:752-6. 
5 Crawley EM, Emond AM, Sterne JAC. Unidentified chronic fatigue Syndrome/myalgic encephalomyelitis (CFS/ME) is a major cause of school absence: surveillance outcomes from school-based clinics. BMJ Open 2011;1:e000252.

6 May M, Emond A, Crawley E. Phenotypes of chronic fatigue syndrome in children and young people. Arch Dis Child 2010;95:245-9.

7 Collin SM, Nuevo R, van de Putte EM, et al. Chronic fatigue syndrome (CFS) or myalgic encephalomyelitis (ME) is different in children compared to in adults: a study of UK and Dutch clinical cohorts. BMJ Open 2015;5:e008830.

8 Perquin CW, Hazebroek-Kampschreur AA, Hunfeld JA, et al. Pain in children and adolescents: a common experience. Pain 2000;87:51-8.

9 Crawley E, Collin SM, White PD, et al. Treatment outcome in adults with chronic fatigue syndrome: a prospective study in England based on the CFS/ME National outcomes database. QJM 2013;106:555-65.

10 Winger A, Kvarstein G, Wyller VB, et al. Pain and pressure pain thresholds in adolescents with chronic fatigue syndrome and healthy controls: a cross-sectional study. BMJ Open 2014;4:e005920.

11 NICE. Chronic fatigue syndrome/myalgic encephalomyelitis (or encephalopathy): diagnosis and management of CFS/ME in adults and children (NICE guidelines CG53). London, 2007. Report No: CG53.

12 Moher D, Liberati A, Tetzlaff J, et al. Preferred reporting items for systematic reviews and meta-analyses: the PRISMA statement. PLoS Med 2009;6:e1000097.

13 Higgins JPT, Thomas J, Chandler J, et al, eds. Cochrane Handbook for Systematic Reviews of Interventionsversion 6.0. Cochrane, 2019. www.training.cochrane.org/handbook.

14 Fukuda K, Straus SE, Hickie I, et al. The chronic fatigue syndrome: a comprehensive approach to its definition and study. International chronic fatigue syndrome Study Group. Ann Intern Med 1994;121:953-9.

15 Sharpe MC, Archard LC, Banatvala JE, et al. A report--chronic fatigue syndrome: guidelines for research. $J R$ Soc Med 1991;84:118-21.

16 Sterne JAC, Savović J, Page MJ, et al. Rob 2: a revised tool for assessing risk of bias in randomised trials. BMJ 2019;366:14898.

17 Sterne JAC, Hernán MA, Reeves BC, et al. ROBINS-I: a tool for assessing risk of bias in non-randomised studies of interventions. BMJ 2016;355:i4919.

18 Crawley E, Mills N, Hollingworth W, et al. Comparing specialist medical care with specialist medical care plus the lightning process for chronic fatigue syndrome or myalgic encephalomyelitis (CFS/ $M E)$ : study protocol for a randomised controlled trial (SMILE trial). Trials 2013;14:444.

19 Crawley EM, Gaunt DM, Garfield K, et al. Clinical and costeffectiveness of the lightning process in addition to specialist medical care for paediatric chronic fatigue syndrome: randomised controlled trial. Arch Dis Child 2018;103:155-64.

$20 \mathrm{Knoop} \mathrm{H}$, Stulemeijer M, Prins JB, et al. Is cognitive behaviour therapy for chronic fatigue syndrome also effective for pain symptoms? Behav Res Ther 2007:45:2034-43.

21 Nijhof SL, Priesterbach LP, Bleijenberg G, et al. Functional improvement is accompanied by reduced pain in adolescent chronic fatigue syndrome. Pain Med 2013;14:1435-8.

22 Sulheim D, Fagermoen E, Winger A, et al. Disease mechanisms and clonidine treatment in adolescent chronic fatigue syndrome: a combined cross-sectional and randomized clinical trial. JAMA Pediatr 2014;168:351-60.

23 van Geelen SM, Fuchs CE, Sinnema G, et al. Self-investigation in adolescent chronic fatigue syndrome: narrative changes and health improvement. Patient Educ Couns 2011;83:227-33.

24 Al-Haggar MS, Al-Naggar ZA, Abdel-Salam MA. Biofeedback and cognitive behavioural therapy for Egypian adolescents suffering from chronic fatigue syndrome. J Paediatric Neurol 2006;4:8.

25 Ashby B, Wright B, Jordan J. Chronic fatigue syndrome: an evaluation of a community based management programme for adolescents and their families. Child Adolesc Ment Health 2006;11:13-18.

26 Chalder T, Tong J, Deary V. Family cognitive behaviour therapy for chronic fatigue syndrome: an uncontrolled study. Arch Dis Child 2002;86:95-7.

27 Chalder T, Deary V, Husain K, et al. Family-focused cognitive behaviour therapy versus psycho-education for chronic fatigue syndrome in 11- to 18-year-olds: a randomized controlled treatment trial. Psychol Med 2010;40:1269-79.
28 Gordon B, Lubitz L. Promising outcomes of an adolescent chronic fatigue syndrome inpatient programme. J Paediatr Child Health 2009;45:286-90.

29 Gordon BA, Knapman LM, Lubitz L. Graduated exercise training and progressive resistance training in adolescents with chronic fatigue syndrome: a randomized controlled pilot study. Clin Rehabil 2010;24:1072-9.

30 Khawaja SS, Van Boxel P. Chronic fatigue syndrome in childhood: seven-year follow-up study. Psychiatric Bulletin 1998;22:198-202.

$31 \mathrm{Knoop} \mathrm{H}$, Stulemeijer M, de Jong LWAM, et al. Efficacy of cognitive behavioral therapy for adolescents with chronic fatigue syndrome: long-term follow-up of a randomized, controlled trial. Pediatrics 2008;121:e619-25.

32 Lim A, Lubitz L. Chronic fatigue syndrome: successful outcome of an intensive inpatient programme. $J$ Paediatr Child Health 2002;38:295-9.

33 Lloyd S, Chalder T, Rimes KA. Family-focused cognitive behaviour therapy versus psycho-education for adolescents with chronic fatigue syndrome: long-term follow-up of an RCT. Behav Res Ther 2012;50:719-25.

34 Lloyd S, Chalder T, Sallis HM, et al. Telephone-based guided self-help for adolescents with chronic fatigue syndrome: a nonrandomised cohort study. Behav Res Ther 2012;50:304-12.

35 Loades ME, Chalder T, Same CT. Same, same but different? Cognitive behavioural treatment approaches for paediatric CFS/ ME and depression - CORRIGENDUM. Behav Cogn Psychother 2017;45:432.

36 Nijhof SL, Bleijenberg G, Uiterwaal CSPM, et al. Effectiveness of Internet-based cognitive behavioural treatment for adolescents with chronic fatigue syndrome (FITNET): a randomised controlled trial. Lancet 2012;379:1412-8.

37 Nijhof SL, Priesterbach LP, Uiterwaal CSPM, et al. Internet-based therapy for adolescents with chronic fatigue syndrome: long-term follow-up. Pediatrics 2013;131:e1788-95.

38 Rimes KA, Papadopoulos AS, Cleare AJ, et al. Cortisol output in adolescents with chronic fatigue syndrome: pilot study on the comparison with healthy adolescents and change after cognitive behavioural guided self-help treatment. J Psychosom Res 2014;77:409-14.

39 Rowe KS. Double-blind randomized controlled trial to assess the efficacy of intravenous gammaglobulin for the management of chronic fatigue syndrome in adolescents. J Psychiatr Res 1997;31:133-47.

40 Rowe KS. Five-Year follow-up of young people with chronic fatigue syndrome following the double blind randomised controlled intravenous gammaglobulin trial. J Chronic Fatigue Syndr 1999;5:97-107

41 Stulemeijer M, de Jong LWAM, Fiselier TJW, et al. Cognitive behaviour therapy for adolescents with chronic fatigue syndrome: randomised controlled trial. BMJ 2005;330:14.

42 Viner R, Gregorowski A, Wine C, et al. Outpatient rehabilitative treatment of chronic fatigue syndrome (CFS/ME). Arch Dis Child 2004;89:615-9.

43 Wright B, Ashby B, Beverley D, et al. A feasibility study comparing two treatment approaches for chronic fatigue syndrome in adolescents. Arch Dis Child 2005;90:369-72.

44 van Geelen SM, Bakker RJ, Kuis W, et al. Adolescent chronic fatigue syndrome: a follow-up study. Arch Pediatr Adolesc Med 2010;164:810-4.

45 Price DD, McGrath PA, Rafii A, et al. The validation of visual analogue scales as ratio scale measures for chronic and experimental pain. Pain 1983;17:45-56.

46 Witherspoon D, Drotar D, Greenley R, et al. Exploratory and confirmatory factor analyses of the child health Questionnaire-Child form 87 (CHQ-CF87) with children chronic conditions and healthy children. J Dev Behav Pediatr 2006;27:448.

47 Cleeland CS, Ryan KM. Pain assessment: global use of the brief pain inventory. Ann Acad Med Singapore 1994;23:129-38.

48 Nijhof SL, Bleijenberg G, Uiterwaal CSPM, et al. Fatigue In Teenagers on the interNET--the FITNET Trial. A randomized clinical trial of web-based cognitive behavioural therapy for adolescents with chronic fatigue syndrome: study protocol. [ISRCTN59878666]. BMC Neurol 2011;11:23.

49 Brigden A, Beasant L, Hollingworth W, et al. Managed activity graded exercise iN teenagers and pre-Adolescents (magenta) feasibility randomised controlled trial: study protocol. BMJ Open 2016;6:e011255. 